VOL. 3 NO. 2 (2020) : 61-67

\title{
PENERAPAN COOPERATIVE LEARNING TIPE TAPPS MENGGUNAKAN BAHAN AJAR GAMIFIKASI TERHADAP PENALARAN MATEMATIS DITINJAU DARI KEPERCAYAAN DIRI PESERTA DIDIK KELAS VIII SMP
}

\author{
Yulita Anggun Sari ${ }^{1}$, Mohammad Muhassin ${ }^{2}$, Indah Resti Ayuni Suri ${ }^{3}$ dan Rizki \\ Wahyu Yunian Putra ${ }^{4}$ \\ Universitas Islam Negeri Raden Intan Lampung, yulitaanggun@ gmail.com ${ }^{1}$ \\ Universitas Islam Negeri Raden Intan Lampung, mohamadmuhasin@ radenintan.ac.id ${ }^{2}$ \\ Universitas Islam Negeri Raden Intan Lampung, ayuni_suri@yahoo.com ${ }^{3}$ \\ Universitas Islam Negeri Raden Intan Lampung, rizkiwahyuyp@ radenintan.ac.id ${ }^{4}$ \\ Received: 3 Juni 2020, Revised : 3 September 2020, Accepted : 30 Oktober 2020 \\ (C) Mathematics Education Unugiri 2020
}

\begin{abstract}
This research aims to determine the influence between the application of TAPPS type cooperative learning using gamification teaching materials and conventional learning, the difference between high, medium, and low Self Confidence, and the interaction between TAPPS type cooperative learning and Self Confidence toward the ability of mathematical reasoning. This research used a quasi-experimental method and subjects of SMP Negeri 1 Natar Lampung Selatan with 64 students. The sample class used were two classes by using Cluster Random Sampling. Hypothesis testing conducted in this research uses two-way ANAVA with $\propto=5 \%$. The results showed: (1) learning using TAPPS type cooperative learning using gamification teaching materials is more effective than learning with conventional methods, (2) there is a self-confidence effect on mathematical reasoning abilities, high Self Confidence is better than medium and low self-confidence and the ability of mathematical reasoning with medium Self Confidence is better than low Self Confidence, (3) there was no interaction between TAPPS type cooperative learning and Self Confidence in mathematical reasoning abilities.
\end{abstract}

Keywords: Cooperative Learning tipe TAPPS, gamification, Mathematical Reasoning, Self Confidence.

\begin{abstract}
Abstrak
Penelitian ini bertujuan untuk mengetahui apakah terdapat pengaruh antara penerapan cooperative learning tipe TAPPS menggunakan bahan ajar gamifikasi dan pembelajaran konvensional, perbedaan antara kepercayaan diri yang tinggi, sedang dan rendah, dan interaksi antara cooperative learning tipe TAPPS dan kepercayan diri terhadap kemampuan penalaran matematis siswa SMP. Jenis penelitian in adalah Quasy Eksperimental, Penelitian dilakukan di SMP Negeri Natar Lampung Selatan dengan jumlah siswa 64. Sampel kelas yang digunakan adalah dua kelas dengan menggunakan teknik Cluster Random Sampling. Pengujian hipotesis menggunakan ANAVA dua arah dengan $\alpha=5 \%$. Hasil penelitian ini adalah: (1) Cooperative learning tipe TAPPS menggunakan bahan ajar gamifikasi lebih berpengaruh daripada pembelajaran konvensional terhadap kemampuan penalaran matematis (2) Kemampuan penalaran matematis dengan kepercayaan diri yang tinggi lebih baik daripada kepercayaan diri sedang dan rendah serta kemampuan penalaran matematis dengan kepercayaan diri yang sedang lebih baik daripada kepercayaan diri rendah (3) Tidak ada interaksi antara cooperative learning tipe TAPPS dan kepercayaan diri terhadap kemampuan penalaran matematis.
\end{abstract}

Kata Kunci : Cooperative Learning tipe TAPPS, gamifikasi, Penalaran Matematis, Kepercayaan Diri. 


\section{Pendahuluan}

Matematika merupakan sumber ilmu yang paling penting karena dari matematika telah berkembang berbagai aspek ilmu lain. Selain itu matematika juga dapat membentuk sikap dan pola pikir. Mengacu pada tujuan pembelajaran matematika yang termuat dalam Permendiknas No. 22 Tahun 2006, salah satunya adalah untuk melatih pada pola pikir dan bernalar dalam menarik kesimpulan yang sesuai dengan logika dengan cara mengamati situasi dan konsep yang nyata.

Berdasarkan salah satu tujuan tersebut dapat dimaknai bahwa peserta didik harus memiliki kemampuan dalam bernalar yang baik. Ini berarti penalaran sangat dibutuhkan pada proses pembelajaran matematika agar materi dalam pembelajaran matematika akan lebih mudah dimengerti. Dengan kata lain, materi dalam pelajaran matematika dan juga penalaran merupakan dua hal yang tidak dapat dipisahkan [1].

Penalaran merupakan proses dalam berpikir seseorang yang dihubungkan melalui fakta-fakta agar dapat ditarik suatu kesimpulan. Materi matematika dianggap mampu dipahami lebih mendalam dengan penalaran dan penalaran juga dapat terus diasah melalui proses belajar mengajar dalam pembelajaran matematika [2].

Namun dari data yang penulis dapatkan di lapangan bahwasannya penalaran matematis yang dimiliki siswa SMP Negeri 1 Natar masih sangat rendah. Hal ini tampak nyata dari hasil nilai uji pra penelitian yang penulis lakukan di SMP Negeri 1 Natar yang rata-rata masih dibawah nilai kriteria ketuntasan minimum yaitu 71 .

Penulis juga melakukan wawancara dengan salah satu guru pengampu mata pelajaran matematika diperoleh informasi bahwa penalaran matematis siswa dalam menyelesaikan soal masih rendah khususnya ketika siswa dihadapkan pada soal yang lebih kompleks dan dalam bentuk cerita. Selain itu pendekatan yang digunakan dalam proses pembelajaran masih cenderung konvensional. Dalam pembelajaran konvensional siswa dituntut untuk banyak mendengarkan sehingga siswa kurang aktif dalam proses pembelajaran. Diperlukan juga adanya bahan ajar yang variatif sehingga dapat membantu seluruh siswa dalam memahami pembelajaran. Ini berarti Penalaran matematis merupakan salah satu aspek yang penting dalam pembelajaran matematika. Penalaran merupakan proses yang digunakan dalam pembelajaran untuk menghubungkan faktafakta yang telah diketahui agar dapat ditarik suatu kesimpulan [3].

Materi dalam pembelajaran matematika akan lebih mudah dimengerti melalui penalaran. Meningkatkan penalaran matematis dianggap sangat penting dan merupakan salah satu dari tujuan matematika itu sendiri. Sebagaimana Depdiknas menyatakan bahwa materi matematika dan penalaran matematis merupakan dua hal yang sangat berhubungan karena memahami materi matematika dapat dilalui dengan cara bernalar dan penalaran pun dapat dilatih melalui pembelajaran matematika.

Claparade pertama kali memperkenalkan Cooperative Learning tipe TAPPS yang pada awalnya digunakan sebagai penelitian oleh Bloom dan Broder untuk mengetahui proses dari pemecahan masalah [4]. Model TAPPS dapat membantu peserta didik dalam hal menghubungkan ide-ide dari permasalahan matematika yang diberikan serta dapat memotivasi peserta didik untuk dapat menemukan kesimpulan atas permasalahan yang ada. Model ini dilakukan melalui diskusi dengan suara keras yang diharapkan pasangan diskusinya mendengar apa yang dipikirkan sehingga dapat merangsang proses berpikir.

Model ini menggambarkan pasangan yang bekerja sama dalam perannya masing-masing yaitu problem solver dan listener untuk memecahkan permasalahan yang diberikan oleh guru [5]. TAPPS atau Thinking Aloud Pair Problem Solving adalah suatu cara dalam proses pembelajaran yang membutuhkan dua peserta didik untuk menyelesaikan suatu permasalahan yang peserta didik temui secara berpasangan dengan tugasnya masing-masing yaitu problem solver sebagai pemecah masalah dan listener sebagai pendengar untuk bekerja secara koperatif dalam memecahkan suatu masalah. Problem solver menjalankan peran untuk menjelaskan tahap demi tahap dalam menyelesaikan masalah yang diberikan guru dalam pembelajaran, sedangkan listener memiliki peran untuk memahami setiap langkah yang dijelaskan oleh problem solver, sementara peran guru hanya mengarahkan siswa agar diskusi dalam kelompok berjalan sesuai dengan prosedur yang telah ditentukan. Setelah berdiskusi peserta didik memperoleh suatu kesimpulan yang disertai dengan bukti terhadap pembelajaran yang telah dilakukan [6]. 
Menurut Lusi Lusiana, Wardani Rahayu dan Ellis Salsabila (2016) dalam penelitiannya mengungkapkan bahwa pemecahan masalah matematis dapat ditingkatkan dengan menerapkan teknik pembelajaran TAPPS. Selain itu penelitian yang dilakukan oleh Nikmatul Maula, Rochmad dan Edy Soedjoko (2013) menunjukkan bahwa kelas ekperimen yang diberikan perlakuan TAPPS memperoleh hasil ketuntasan yang lebih baik dari kelas kontrol.

Bahan ajar gamifikasi merupakan seperangkat bahan ajar yang dalam penyajiannya berisi gambar dan beberapa pertanyaan atau percakapan dan dilengkapi dengan deskripsi dari gambar tersebut untuk menceritakan suatu masalah yang di dalamnya terdapat unsur elemen game yang menarik dan harus siswa selesaikan sesuai dengan materi pembelajaran [7]. Dengan diterapkannya bahan ajar ini materi dari pembelajaran diduga lebih dipahami siswa dan bahan ajar ini membuat siswa menjadi tidak bosan dalam kegiatan pembelajaran matematika karena di dalamnya juga terdapat unsur game dan ilustrasi gambar yang menarik [8].

Faktor eksternal dan faktor internal adalah dua faktor yang secara umum berpengaruh di dalam hasil belajar. Faktor eksternal adalah faktor yang asalnya dari luar sedangkan faktor internal merupakan faktor yang asalnya dari dalam diri peserta didik itu sendiri, salah satunya adalah kepercayaan diri (self confidence). Kepercayaan diri adalah keyakinan hati seseorang agar mampu bertindak sesuai dengan yang diinginkan dan mampu untuk meningkatkan motivasi yang ada dalam diri [9].

Kepercayaan diri adalah unsur penting dalam meraih kesuksesan. kepercayaan diri juga dimaksudkan sebagai keyakinan agar mampu bertindak optimis, objektif, bertanggung jawab, rasional dan realistis [10]. Ada tiga kategori dalam kepercayaan yaitu tinggi, sedang dan rendah.

Penelitian ini memiliki tujuan yang ingin dicapai yakni untuk mengetahui apakah terdapat pengaruh antara cooperative learning tipe TAPPS menggunakan bahan ajar gamifikasi dan pembelajaran konvensional terhadap kemampuan penalaran matematis peserta didik, pengaruh kepercayaan diri tinggi,sedang, dan rendah terhadap kemampuan penalaran matematis serta mengetahui interaksi antara cooperative learning tipe TAPPS dengan kepercayaan diri terhadap kemampuan penalaran matematis peserta didik.

\section{Metode Penelitian}

Penelitian ini menggunakan metode eksperimen semu (Quasi Experimental Design) yang dibagi dalam dua kelompok penelitian yakni kelompok penelitian kelas eksperimen dan kelas kontrol. Untuk kelas eksperimen penulis menerapkan pembelajaran dengan cooperative larning tipe TAPPS menggunakan bahan ajar gamifikasi dan untuk kelas kontrol penulis menerapkan pembelajaran dengan pembelajaran konvensional.

Desain dalam penelitian yang digunakan penulis yaitu Pretest-Posttest Control Grup Design. Penulis melakukan penelitian tepatnya di SMP Negeri 1 Natar. Adapun teknik yang penulis gunakan dalam pengambilan sampel yaitu dengan menggunakan cluster random sampling yaitu siswa kelas VIII F dan VIII G yang semuanya berjumlah 64 siswa. Cluster random sampling yaitu teknik pengambilan sampel yang dilakukan secara acak terhadap kelompok-kelompok unit yang kecil yang berada dalam satu kelompok (cluster) [11]. Untuk kelas VIII G dalam pembelajaran matematika diterapkan cooperative learning tipe TAPPS menggunakan bahan ajar gamifikasi. Kemudian kelas VIII F diterapkan pembelajaran konvensional.

Instrumen yang digunakan di dalam penelitian ini yaitu angket yang berupa 40 butir pernyataan terdiri dari 20 butir pernyataan bernilai positif dan 20 butir pernyataan bernilai negatif serta tes awal dan tes akhir berupa essay dengan 6 butir soal. Sebelum digunakan dalam penelitian, angket dan soal tersebut telah dilakukan uji instrumen dengan kelas yang berbeda. Selanjutnya hasil dari angket telah diolah berdasarkan validitas dan reliabilitas sedangkan nilai tes siswa diolah berdasarkan validitas, reliabilitas, tingkat kesukaran dan daya pembeda untuk melihat apakah soal tersebut layak atau tidak digunakan. Penelitian ini menggunakan teknik analisis data yaitu uji anava dua jalan.

\section{Pembahasan}

Berdasarkan penelitian yang telah dilakukan penulis di SMP Negeri 1 Natar diperoleh hasil nilai pretest, posttest, dan $\mathrm{N}$-gain untuk kedua kelas yang diberi perlakuan berbeda hasilnya juga berbeda. 
Hasil perhitungan dari nilai pretest pada kemampuan penalaran matematis dapat dilihat pada tabel 1 .

Tabel 1. Deskripsi Data Hasil pretest Penalaran Matematis

\begin{tabular}{ccr}
\hline Nilai & \multicolumn{2}{c}{ Kelas } \\
\cline { 2 - 3 } & Eksperimen & Kontrol \\
\hline$X_{\operatorname{maks}}$ & 63,33 & 61,67 \\
$X_{\min }$ & 25,00 & 21,67 \\
$\bar{x}$ & 40,42 & 37,66 \\
$m_{o}$ & 33,33 & 33,33 \\
$m_{e}$ & 38,33 & 35,83 \\
$R$ & 38,33 & 40,00 \\
$S$ & 9,49 & 10,90 \\
\hline
\end{tabular}

Berdasarkan tabel 1 diperoleh hasil pretest yang diberikan pada kelas eksperimen dan kontrol, terlihat bahwa nilai tertinggi pretest pada kelas eksperimen dan kelas kontrol adalah 63,33 dan 61,67 , sedangkan nilai terendahnya adalah 25,00 dan 21,67. Kelas eksperimen memiliki mean sebesar 40,42, modusnya sebesar 33,33, dan mediannya sebesar 38,33 sedangkan kelas kontrol memiliki mean sebesar 37,66, modusnya sebesar 33,33, dan mediannya sebesar 35,83. Kelas eksperimen memiliki rentang dalam ukuran variansi kelompok yaitu sebesar 38,33. Sedangkan kelas kontrol memiliki rentang dalam ukuran variansi kelompok yaitu sebesar 40,00. Untuk simpangan baku kelas eksperimen ialah 9,49 dan untuk kelas kontrol ialah 10,90. Ini berarti bahwa hasil pretest kemampuan penalaran matematis pada kelas eksperimen lebih baik daripada kelas kontrol.

Hasil perhitungan nilai posttest dapat dilihat pada tabel dalam tabel 2 berikut ini:

Tabel 2. Deskripsi Data Hasil posttest Penalaran Matematis

\begin{tabular}{ccr} 
& \multicolumn{2}{c}{ Penalaran Matematis } \\
\hline \multirow{2}{*}{ Nilai } & \multicolumn{2}{c}{ Kelas } \\
\cline { 2 - 3 } & Eksperimen & Kontrol \\
\hline$X_{\operatorname{maks}}$ & 93,33 & 83,33 \\
$X_{\min }$ & 33,33 & 38,33 \\
$\bar{x}$ & 67,34 & 61,41 \\
$m_{o}$ & 41,67 & 41,67 \\
$m_{e}$ & 71,67 & 61,67 \\
$R$ & 60,00 & 45,00 \\
$S$ & 15,80 & 14,88 \\
\hline
\end{tabular}

Berdasarkan tabel 2 diperoleh hasil posttest yang diberikan pada kelas eksperimen dan kelas kontrol, terlihat bahwa nilai tertinggi pada kelas eksperimen dan kelas kontrol adalah 93,33 dan 83,33, sedangkan nilai terendahnya adalah 33,33 dan 38,33. Kelas eksperimen memiliki mean sebesar 67,34, modusnya sebesar 41,67, dan mediannya sebesar 71,67 sedangkan kelas kontrol memiliki mean sebesar 61,41, modusnya sebesar 41,67, dan mediannya sebesar 61,67. Kelas eksperimen memiliki rentang dalam ukuran variansi kelompok yaitu sebesar 60,00. Sedangkan kelas kontrol memiliki rentang dalam ukuran variansi kelompok yaitu sebesar 45,00. Untuk simpangan baku kelas eksperimen ialah 15,80 dan untuk kelas kontrol ialah 14,88. Ini berarti bahwa hasil posttest kemampuan penalaran matematis pada kelas eksperimen lebih baik daripada kelas kontrol.

Selanjutnya hasil perhitungan nilai $N$-Gain yang didapatkan dari hasil pretest dan posttest dapat dilihat pada tabel 3 .

Tabel 3. Deskripsi Data Hasil N-Gain Penalaran Matematis

\begin{tabular}{ccr}
\hline \multirow{2}{*}{ Nilai } & \multicolumn{2}{c}{ Kelas } \\
\cline { 2 - 3 } & Eksperimen & Kontrol \\
\hline$X_{\text {maks }}$ & 0,85 & 0,66 \\
$X_{\min }$ & 0,11 & 0,09 \\
$\bar{x}$ & 0,47 & 0,39 \\
$m_{o}$ & 0,13 & 0,20 \\
$m_{e}$ & 0,52 & 0,38 \\
$R$ & 0,74 & 0,57 \\
$S$ & 0,21 & 0,19 \\
\hline
\end{tabular}

Berdasarkan tabel 3 diperoleh hasil $N$ Gain yang diberikan pada kelas eksperimen dan kontrol, terlihat bahwa nilai tertinggi $N$-Gain pada kelas eksperimen dan kelas kontrol adalah 0,85 dan 0,66 , sedangkan nilai terendahnya adalah 0,11 dan 0,09. Kelas eksperimen memiliki mean sebesar 0,47, modusnya sebesar 0,13, dan mediannya sebesar 0,52 sedangkan kelas kontrol memiliki mean sebesar 0,39, modusnya sebesar 0,20, dan mediannya sebesar 0,38. Kelas eksperimen memiliki rentang dalam ukuran variansi kelompok yaitu sebesar 0,74 . Sedangkan kelas kontrol memiliki rentang dalam ukuran variansi kelompok yaitu sebesar 0,57. Untuk simpangan baku kelas eksperimen ialah 0,21dan untuk kelas kontrol ialah 0,19. Ini berarti bahwa hasil pretest kemampuan penalaran matematis pada kelas eksperimen lebih baik daripada kelas kontrol.

Sebelum melakukan perhitungan pada uji anava dua jalan yang dimaksudkan untuk mengetahui pengaruh dan interaksi dua variable bebas terhadap satu variable terikat [12]. Maka 
peneliti melakukan uji prasyarat yaitu uji normalitas yang dilakukan pada data $\mathrm{N}$-gain terlebih dahulu. Dapat dikatakan normal jika data $L_{\text {hitung }} \leq L_{\text {tabel }}$ maka $H_{0}$ diterima yang berarti data dari hasil perhitungan $N$-Gain yaitu berditribusi normal. Adapun hasil dari uji normalitas pada data $N$-Gain dapat dilihat pada tabel 4 .

Tabel 4. Uji Normalitas N-Gain

\begin{tabular}{cccc}
\hline Perlakuan & $\boldsymbol{L}_{\text {hitung }}$ & $\boldsymbol{L}_{\text {tabel }}$ & $\begin{array}{c}\text { Keputusan } \\
\mathbf{U j i}\end{array}$ \\
\hline $\begin{array}{c}\text { Eksperime } \\
\mathbf{n}\end{array}$ & 0,10487 & 0,15663 & Normal \\
Kontrol & 0,13571 & 0,15663 & Normal \\
KD (R) & 0,12973 & 0,18890 & Normal \\
KD (S) & 0,13988 & 0,16453 & Normal \\
KD (T) & 0,09148 & 0,24574 & Normal \\
\hline
\end{tabular}

Setelah dilakukan uji normal maka dilakukan uji homogenitas. Hasil uji homogenitas terangkum pada tabel 5.

Tabel 5. Uji Homogenitas N-Gain

\begin{tabular}{ccc}
\hline Hasil & $\boldsymbol{A}_{\mathbf{1}}$ dan $\boldsymbol{A}_{\mathbf{2}}$ & $\boldsymbol{B}_{\mathbf{1}}, \boldsymbol{B}_{\mathbf{2}}$ dan $\boldsymbol{B}_{\mathbf{3}}$ \\
\hline$n$ & 32 & 32 \\
$x_{\text {hitung }}^{2}$ & 0,33134 & 0,55629 \\
$x_{\text {tabel }}^{2}$ & 5,991 & 3,841 \\
Kesimpulan & Homogen & Homogen \\
\hline
\end{tabular}

Tabel 5 menunjukkan hasil uji homogenitas $N$-Gain. Jika data $x_{\text {hitung }}^{2}<x_{\text {tabel }}^{2}$ maka $H_{0}$ diterima yang berarti data hasil perhitungan $N$ Gain terebut bersifat homogen yaitu sampel berasal dari populasi yang memiliki variansi yang sama. Berdasarkan tabel data hasil uji homogenitas $N$-gain pada $A_{1}$ dan $A_{2}$ dapat dilihat bahwa besar nilai $x_{\text {hitung }}^{2}=0,33134$ serta $x_{\text {tabel }}^{2}=5,991$. Pada $B_{1}, B_{2}$ dan $B_{3}$ besar nilai $x_{\text {hitung }}^{2}=0,55629$ serta $x_{\text {tabel }}^{2}=3,841$. Kemudian untuk kedua nilai tersebut dibandingkan, karena besar nilai $x_{\text {hitung }}^{2}$ pada $A_{1}$ dan $A_{2}$ serta pada $B_{1}, B_{2}$ dan $B_{3}$ didapatkan $<x_{\text {tabel }}^{2}$ maka $H_{0}$ diterima. Ketika uji Homogen telah dilakukan, maka selanjutnya uji yang digunakan adalah uji anava 2 jalan.

Tabel 6. Rangkuman Analisis Variansi Dua Jalan

\begin{tabular}{cccc}
\hline Kelompok & $\boldsymbol{F}_{\text {hitung }}$ & $\boldsymbol{F}_{\text {tabel }}$ & Kesimpulan \\
\hline Baris & 14,335 & 4,007 & Ditolak \\
Kolom & 59,776 & 3,156 & Ditolak \\
Interaksi & 1,459 & 3,156 & Diterima
\end{tabular}

Tabel 6 menunjukkan hasil uji anava $N$-Gain dua jalan. Jika data $F_{\text {hitung }}>F_{\text {tabel }}$ maka $H_{0}$ ditolak yang berarti terdapat perbedaan berdasarkan hasil data nilai $\mathrm{N}$-gain penalaran matematis peserta didik antara kedua kelas yang penulis gunakan dalam penelitian. Berdasarkan hasil data uji anava $N$-gain dapat dilihat bahwa pada model pembelajaran (A) diperoleh $F_{\text {hitung }}=$ 14,335, dan nilai $F_{\text {tabel }}=4,007$. Jika besar nilai $F_{\text {hitung }}$ dan besar nilai $F_{\text {tabel }}$ dibandingkan maka data nilai $F_{\text {hitung }}=14,335>F_{\text {tabel }}=4,007$ artinya $H_{0}$ ditolak yang artinya terdapat perbedaan berdasarkan hasil $N$-Gain kemampuan penalaran matematis antara kedua kelas yang digunakan dalam penelitian.. Sedangkan untuk kepercayaan diri diperoleh $F_{\text {hitung }}=59,776$ sedangkan $F_{\text {tabel }}=3,156$. Jika $F_{\text {hitung }}$ dan $F_{\text {tabel }}$ dibandingkan maka $F_{\text {hitung }}=59,776>$ $\mathrm{F}_{\text {tabel }}=3,156$ sehingga $H_{O}$ ditolak yang artinya terdapat perbedaan kepercayaan diri antara kedua kelas yang digunakan dalam penelitian. Kemudian dapat diketahui juga bahwa pada interaksi (AB) diperoleh $F_{\text {hitung }}=1,459$ sedangkan $F_{\text {tabel }}=3,156$. Jika $F_{\text {hitung }}$ dan $F_{\text {tabel }}$ dibandingkan maka $F_{\text {hitung }}=1,459<F_{\text {tabel }}=$ 3,156 sehingga $H_{O}$ diterima yang artinya tidak terdapat interaksi antara metode pembelajaran dan kepercayaan diri antara kedua kelas yang digunakan dalam penelitian.

Setelah melakukan perhitungan pada tabel 6, maka perhitungan selanjutnya adalah uji lanjut (Scheffe). Jika data $F_{\text {hitung }}>F_{\text {tabel }}$ maka $H_{0}$ ditolak yang berarti adanya perbedaan yang mendasar antara kepercayaan diri dalam penelitian.

Tabel 7. Rangkuman Rataan Marginal

\begin{tabular}{|c|c|c|c|c|}
\hline \multirow{2}{*}{$\begin{array}{c}\text { Model } \\
\text { Pembelaj } \\
\text { aran }\end{array}$} & \multicolumn{3}{|c|}{ Kepercayaan Diri } & \multirow{2}{*}{$\begin{array}{c}\text { Rataa } \\
\text { n } \\
\text { Marg } \\
\text { nal }\end{array}$} \\
\hline & $\begin{array}{c}\text { Renda } \\
\text { h }\end{array}$ & $\begin{array}{c}\text { Sedan } \\
\mathrm{g}\end{array}$ & $\begin{array}{c}\text { Ting } \\
\text { gi }\end{array}$ & \\
\hline$\left(\mu_{1}\right.$ vs $\left.\mu_{2}\right)$ & 0,28 & 0,52 & 0,72 & 0,51 \\
\hline$\left(\mu_{1}\right.$ vs $\left.\mu_{3}\right)$ & 0,19 & 0,47 & 0,55 & 0,40 \\
\hline$\left(\mu_{2} \operatorname{vs} \mu_{3}\right)$ & 0,23 & 0,50 & 0,64 & \\
\hline
\end{tabular}

Tabel rangkuman rataan marginal digunakan untuk melihat kepercayaan diri mana yang paling baik terhadap penalaran matematis. Berdasarkan rataan marginal, dimana rataan kelompok peserta didik yang menerapkan 
cooperative learning tipe TAPPS lebih tinggi yaitu 0,51 daripada rataan kelompok siswa pada kelas kontrol yaitu 0,40. Maka dapat disimpulkan metode TAPPS lebih baik daripada metode konvensional. Selain itu, uji komparasi ganda antar kolom dengan model Scheffe perlu diujikan agar dapat diketahui sejauh mana yang secara signifikan memiliki rataan yang berbeda. Hasil dari uji komparasi ganda antar kolom dapat diamati pada tabel 8.

Tabel 8. Rangkuman Uji Komparasi Ganda antar Kolom

\begin{tabular}{cccc}
\hline Interaksi & $\boldsymbol{F}_{\text {hitung }}$ & $\boldsymbol{F}_{\text {tabel }}$ & Kesimpulan \\
\hline$\left(\mu_{1}\right.$ vs $\left.\mu_{2}\right)$ & 56,998 & 3,156 & Ditolak \\
$\left(\mu_{1}\right.$ vs $\left.\mu_{3}\right)$ & 85,851 & 3,156 & Ditolak \\
$\left(\mu_{2}\right.$ vs $\left.\mu_{3}\right)$ & 11,7365 & 3,156 & Diterima \\
\hline
\end{tabular}

Antara kepercayaan diri rendah dengan kepercayaan diri sedang $\left(\mu_{1}\right.$ vs $\left.\mu_{2}\right)$ diperoleh $F_{1-2}=56,998$ dengan $F_{\text {tabel }}=3,156$ sedangkan $D K=\{F \mid F>3,156\}$ sehingga $H_{0}$ ditolak. Jadi dapat disimpulkan bahwa ada perbedaan antara kepercayaan diri rendah dengan kepercayaan diri sedang terhadap kemampuan penalaran matematis. Berdasarkan pada tabel 7 diketahui rataan marginal peserta didik dengan kepercayaan diri sedang yaitu 0,50 jika dibandingkan lebih besar dengan dengan kepercayaan diri rendah yaitu 0,23 terhadap kemampuan penalaran matematis. kepercayaan diri rendah dengan kepercayaan diri tinggi $\left(\mu_{1}\right.$ vs $\left.\mu_{3}\right)$ diperoleh $F_{1-3}=85,851$ dengan $F_{\text {tabel }}=3,156$ sedangkan $D K=\{F \mid F>3,156\}$ sehingga $H_{0}$ ditolak. Jadi dapat disimpulkan bahwa ada perbedaan antara peserta didik kepercayaan diri rendah dengan kepercayaan diri tinggi terhadap kemampuan penalaran matematis. Berdasarkan pada tabel 7 diketahui rataan marginal peserta didik dengan kepercayaan diri tinggi yaitu 0,64 jika dibandingkan lebih besar dengan kepercayaan diri rendah yaitu 0,23 terhadap terhadap kemampuan penalaran matematis. Kemudian antara kepercayaan diri sedang dengan kepercayaan diri tinggi $\left(\mu_{2}\right.$ vs $\left.\mu_{3}\right)$ diperoleh $F_{2-3}=11,7365 \quad$ dengan $\quad F_{\text {tabel }}=3,156$ sedangkan $D K=\{F \mid F>3,156\}$ sehingga $H_{0}$ ditolak. Jadi dapat disimpulkan bahwa ada perbedaan antara kepercayaan diri sedang dengan kepercayaan diri tinggi terhadap kemampuan penalaran matematis. Berdasarkan pada tabel 7 diketahui rataan marginal peserta didik dengan kepercayaan diri tinggi yaitu 0,64 jika dibandingkan lebih besar dengan kepercayaan diri 66 sedang yaitu 0,50 terhadap kemampuan penalaran matematis.

\section{Penutup}

Berdasarkan hasil dari analisis data dan pembahasan, maka didapatkan kesimpulan bahwa terdapat pengaruh cooperative learning tipe TAPPS menggunakan bahan ajar gamifikasi terhadap kemampuan penalaran matematis. Kemampuan penalaran matematis pada cooperative learning tipe TAPPS yang menggunakan bahan ajar gamifikasi lebih baik dibanding dengan pembelajaran konvensional. Selain itu, terdapat pengaruh untuk peserta didik yang masing-masing memiliki kepercayaan diri rendah, sedang, dan tinggi terhadap kemampuan penalaran matematisnya, di mana kemampuan penalaran matematis peserta didik yang memiliki kepercayaan diri tinggi lebih baik daripada peserta didik yang memiliki kepercayaan diri sedang ataupun kepercayaan diri rendah serta tidak terdapat interaksi antara cooperative learning tipe TAPPS dengan kepercayaan diri peserta didik terhadap kemampuan penalaran matematis.

Penulis juga menyarankan bagi pendidik hendaknya dapat menggunakan cooperative learning tipe TAPPS karena telah terbukti berpengaruh pada aspek penalaran matematis peserta didik, serta dapat lebih selektif dalam memilih bahan ajar yang variatif seperti bahan ajar gamifikasi agar peserta didik tidak jenuh dalam memahami pelajaran.

\section{Referensi}

[1] Sumartini, T. S. Peningkatan kemampuan penalaran matematis siswa melalui pembelajaran berbasis masalah. Mosharafa: Jurnal Pendidikan Matematika, 4(1) (2015) 110.

[2] Kani, N. H. A., \& Shahrill, M. Applying the thinking aloud pair problem solving strategy in mathematics lessons. Asian Journal of Management Sciences and Education, 4(2), (2015) 20-28.

[3]Sukamto, "Strategi Quantum Learning dengan Pendekatan Konstruktivisme Untuk Meningkatkan Disposisi dan Penalaran Matematis Siswa", (Jurnal of primary education, Universitas Negeri semarang, JP, (2013)

[4] Lusi Lusiyana Aminah, Wardani Rahayu, dan Ellis Salsabila, "Penerapan Teknik Pembelajaran Thinking Aloud Pair Problem 
Solving (TAPPS) Untuk Meningkatkan Kemampuan Pemecahan Masalah Matematis Pada Pokok Bahasan Kubus Dan Balok Di Kelas Viii-5 Smp Negeri 27 Jakarta," (2015). t.t., 10.

[5] Yanuarti, M., Usodo, B., \& Riyadi, R. Eksperimentasi Model Pembelajaran Kooperatif Tipe Think Pair Share (Tps) dan Thinking Aloud Pairs Problem Solving (TAPPS) pada Materi Bangun Ruang Sisi Datar Ditinjau dari Sikap Percaya Diri Siswa SMPN Kabupaten Sukoharjo. Jurnal Pembelajaran Matematika, (2014) 2(10).

[6] Pate, M.L., Wardlow, G.W \& Johnson, D.M. Effects Of Thinking Aloud Pair Problem Solving On The Troubleshooting Performance In A Power Technology Course. Journal of Agricultural Education 45. (2004)

[7] Rembulan, A., \& Putra, R. W. Y. Pengembangan Bahan Ajar Gamifikasi pada Materi Statistika Kelas VIII. JMPM: Jurnal Matematika dan Pendidikan Matematika, 3(2) (2019)

[8] Heni Jusuf, "Peggunaan Gamifikasi dalam Proses Pembelajaran" 5 (2016) 6.

[9] Amalia, Y., Duskri, M., \& Ahmad, A. "Penerapan Model Eliciting Activities untuk Meningkatkan Kemampuan Berpikir Kreatif Matematis dan Self Confidence Siswa SMA". Jurnal Didaktik Matematika,2(2). (2015)

[10]Ghufron,dkk. Teori-Teori Psikologi. Jogjakarta: Ar-Ruzz Media. (2011)

[11] Sugiyono. Metode Penelitian Pendidikan. Bandung : Alfabeta. (2017).

[12]Novalia, M. S., \& Syazali, M. (2014). Olah Data Penelitian Pendidikan. Bandar Lampung: Anugrah Utama Rahaja. 
http://journal.unugiri.ac.id/index.php?journal=JaMES 